\title{
Você não responde ao perfil: representações sociais sobre o mercado de trabalho para transexuais
}

\section{You do not fit the profile: social representations about the labor market for transexuals}

\section{Ronilto Arthur Gonçalves Lopes ${ }^{1}$ (1) Cristina Adriana Rodrigues Kern ${ }^{2}$ (1) Gabriela Pereira Vidal ${ }^{3}$ (1) Amanda Castro 4 (1)}

\author{
1Viver Mais Psicologia (Tubarão). Santa Catarina, Brasil. psicologoarthurlopes@gmail.com \\ ¿Universidade do Extremo Sul Catarinense (Criciúma). Santa Catarina, Brasil. cristinak@unesc.net \\ 3Viver Mais Psicologia (Tubarão). Santa Catarina, Brasil. gabrielavidaal@gmail.com \\ ${ }^{4}$ Universidade do Extremo Sul Catarinense (Criciúma), Universidade Estácio de Sá (Florianópolis), Viver Mais Psicologia (Tubarão).
} Santa Catarina, Brasil. amandacastrops@gmail.com

\begin{abstract}
RESUMO | Este artigo propôs levantar as representações sociais de transexuais no mercado de trabalho, percebendo este também como constituinte da identidade do indivíduo. Os participantes foram dois homens e três mulheres transexuais, com idade entre 18 e 47 anos, moradores da região AMREC - Associação dos Municípios da Região Carbonífera de Santa Catarina. Na coleta de dados, utilizou-se a técnica Projeção de Futuro, que permitiu os relatos e dramatizações das cenas das representações profissionais. O conteúdo foi analisado no software IRAMUTEQ, em classes de segmentos de textos e as principais classes foram "Experiências de trabalho no futuro e no passado" e a "Percepção Social", cada uma com $25 \%$ de segmentos de texto. Com o acesso às representações sociais de transexuais, foi possível perceber a influência que o preconceito social tem na formação da carreira da população que serviu de amostra para essa pesquisa.
\end{abstract}

PALAVRAS-CHAVE: Identidade de gênero. Representação social. Trabalho.

\begin{abstract}
This article proposes to raise as social representations of transsexuals in the labor market, also perceiving it as a constituent of the individual's identity. The participants were two men and three transsexual women, aged between 18 and 47 years old, living in the AMREC region of Santa Catarina, Brazil. In data collection, use a Future Projection technique, which allows reports and dramatizations of scenes from professional representations. The content was analyzed using the IRAMUTEQ software, in the text topic classes and the main classes were "Work experiences in the future and in the past" and "Social Perception", each with 25\% text segments. With the access to social representations of transsexuals, it was possible to perceive the influence that prejudice has on the formation of the career of the population that served as a sample for that research.
\end{abstract}

KEYWORDS: Gender identity. Social representation. Job. 


\section{Introdução}

Nas últimas décadas ampliaram-se e até mesmo iniciaram-se diversas discussões acerca da diversidade de gênero, dando visibilidade ao tema e afunilando temáticas específicas. Diante disso, houve avanços no cotidiano das pessoas transexuais, avanços estes que podem ser considerados grandes quanto a importância e dificuldade desse espaço, mas pequenos quando pensa-se no caminho que ainda é necessário (Goerch \& Silva, 2019).

Ainda hoje observamos um aumento considerável da LGBTfobia, sigla que representa a comunidade composta por lésbicas, gays, bissexuais, travestis e transexuais. Segundo o Grupo Gay da Bahia (GGB), primeira associação em defesa dos direitos gays no Brasil, pelo menos 343 pessoas LGBTs foram assassinadas no ano de 2016. O relatório afirma ainda que $40 \%$ das mortes mundiais de transexuais e travestis foram cometidas no Brasil, nesse último ano. É possível observar, através da pesquisa realizada pela associação, que a maioria das vítimas transexuais e travestis eram profissionais do sexo, estando, assim, mais expostas à criminalidade (Cerqueira, 2016).

No entanto, isso não quer dizer que demais transexuais que não trabalham com prostituição estejam livres do crime. Vivendo numa sociedade capitalista, compreende-se que o trabalho seja uma das maiores fontes de satisfação das necessidades humanas, seja em relação ao desenvolvimento do espaço pessoal, à interação social ou ao lucro obtido. Dessa forma:

\section{Se, para a sobrevivência, o trabalho deveria satisfazer} pelo menos as necessidades básicas diárias, na perspectiva psicológica é uma categoria central no desenvolvimento do autoconceito e uma fonte de autoestima. É a atividade fundamental para o desenvolvimento do ser humano. Em suma, é um forte componente na construção da pessoa que convive bem consigo mesma, acredita e orgulha-se de si (Zanelli \& Silva, 1996, p. 21).

Salientando que o trabalho é um direito e uma necessidade na sociedade atual, verifica-se que as pessoas transexuais estão completamente desamparadas em relação a isso. Segundo Bento (2008) o Estado é o responsável direto pela dificuldade de inserção das travestis e transexuais no mercado de trabalho. Ainda de acordo com a autora, faltam políticas públicas em defesa desse grupo de pessoas e, tendo elas o direito de ir e vir com segurança já negligenciado, pensar no direito de trabalho se torna ainda mais delicado.

Outro ponto importante de se destacar é o caso do nome civil. Vasconcellos (2014) aponta em sua pesquisa que existem juízes que não autorizam a alteração do nome, e outros que, por sua vez, liberam o nome mesmo para pessoas que não têm o interesse pela cirurgia completa. Mesmo fazendo parte dos direitos humanos, a maioria das pessoas que conseguem mudar o nome civil são transexuais com laudos psicológicos que comprovaram o estado da identidade de gênero, como um transtorno patológico.

Silva, Luppi e Veras (2020), em estudo recente e relacionado a fatores associados ao trabalho e a saúde na população transexual, destacam em seus resultados o baixo percentual de inserção dessa população no mercado de trabalho formal, demonstrando essa vulnerabilidade. As autoras também enfatizaram, como possibilidades de inserção no mercado de trabalho "as políticas públicas de inclusão escolar, tolerância e respeito à diversidade de identidade de gênero nas instituições de ensino, para reverter o cenário de abandono escolar e consequentemente baixa escolaridade" (p. 1731). Além disso, destacam ainda o acesso ao processo transexualizador no Sistema Único de Saúde, como uma das ações importantes e necessárias visando a redução das desigualdades vivenciadas por essa população.

Tendo em vista então, o conceito patológico e preconceituoso atribuído pela sociedade e pela ciência às transexuais, à grande taxa de crimes transfóbicos e à dificuldade do acesso ao nome civil e ao mercado de trabalho, mostra-se importante identificar as contribuições de uma pesquisa com transexuais para compreender suas representações sociais acerca do mercado de trabalho e propiciar sua prospecção do futuro. O objetivo geral da presente pesquisa é analisar as representações sociais de transexuais acerca do mercado de trabalho, enquanto os específicos estão relacionados à caracterização das experiências dessa população no mercado de trabalho, sejam as do passado e as projeções sobre o futuro.

\section{Representação Social}

Para Jodelet (2001) as representações sociais representam uma maneira de conhecimento, de saber, que é constituída e compartilhada de forma social. 
O termo Representações Sociais foi abordado por Moscovici (1978) ao estudar o modelo da sociedade na construção de representações compartilhadas sobre os fenômenos, com o intuito de entender a realidade, sendo conceituado então como forma de conhecimento socialmente construída e compartilhada.

De acordo com Moscovici (1978) sem comunicação e sem partilha de representações, é impossível estabelecer conhecimento. Portanto, para que o fenômeno até então desconhecido seja acomodado, torna-se necessário uma comunicação entre ele e o indivíduo, para que ele consiga acomodar esse movimento em algo agora conhecido (Moscovici, 1978).

Almeida (2000) aponta que as representações sociais são formas de conhecimento prático e possuem funções diferentes do conhecimento científico e seriam elas a de saber (conhecer o objeto), identitária (se reconhecer em um grupo), orientação (saber como agir) e de justificação (dizer a razão da ação). Concomitantemente, Abric (1998), coloca que as representações sociais possuem papel fundamental na dinâmica das relações e nas práticas sociais, em que práticas sociais influenciam em representações e representações influem em práticas. E é seguindo essa premissa que se mostra necessário identificar as representações sociais do mercado de trabalho para transexuais, para que pudesse desconstruir práticas e representações discriminatórias.

\section{Preconceito Social}

O termo preconceito, de acordo com Allport (1979), é considerado uma atitude hostil ou de prevenção direcionada a uma pessoa pertencente a um grupo, apenas pelo fato de pertencer a tal grupo, supondo que possui as mesmas características que ele. Ainda sobre a discriminação, os autores citam como manifestação do preconceito, onde o grupo ou indivíduo são impossibilitados de acessar seus direitos sociais.

Segundo Garcia (2008, p. 6) "a história da homossexualidade, a partir do século XIX, é marcada pelas concepções médicas e jurídicas, que a consideravam ao mesmo tempo uma doença e uma conduta condenável, passível de punição". Além disso, o autor ainda descreve que desde então, até a metade do século $\mathrm{XX}$, os sistemas policial e jurídico buscavam meios de incluir a homossexualidade como crime e mesmo não conseguindo nada baseado em lei regulamenta$\mathrm{da}$, o grupo foi constantemente perseguido e punido, seja por alegação de atentado ao pudor ou por relação com o uso de drogas.

Na época citada, todo o grupo caracterizado como homossexuais (travestis, transexuais, lésbicas, nãobinários), eram perseguidos, e na maioria dos casos, os tidos como afeminados eram os mais focados. Era comum também a perseguição às prostitutas, que por muito tempo foram relacionadas a todo tipo de referência criminal, tendo também o estereótipo de "ilegal" articulado a sua identidade (Rago, 1991).

O Brasil mostra em sua identidade cultural a homofobia naturalizada, visto que, desde 2002 existe um projeto de lei, ainda não aprovado, que visa criminalizar as atitudes homofóbicas. Dessa forma, os crimes de cunho homofóbicos são passíveis de julgamento apenas por outros segmentos, como homicídio simples, por exemplo, não levando em questão o real motivo dos ocorridos: a estigmatização da população LGBT (Gomes, 2009). Sobre o estigma, este pode estar relacionado ao fato de encontrarmos algum atributo diferente no outro, algo que o torne diferente ou algo menos desejável. Dessa forma, a pessoa passa a deixar de ser um ser em sua completude, sendo reduzida ao estigma que esse atributo a impõe (Goffman, 2004).

Essa discriminação é maior quando nos referimos a transfobia, conceituada como a aversão direta contra travestis e transgêneros, ou seja, a não aceitação da separação da identidade de gênero com o gênero biológico. Para reforçar essa hipótese os autores abaixo comparam em suas pesquisas a quantidade de homossexuais, travestis e transexuais com as taxas de assassinatos do ano:

Sempre é bom insistir que proporcionalmente as travestis são muito mais vitimizadas do que lésbicas e gays, pois a população de transgêneros no Brasil deve oscilar entre 10 a 20 mil indivíduos (para um total de 32 homicídios), enquanto os gays devem ultrapassar 17 milhões (para 90 vítimas) (Mott \& Cerqueira, 2003, p. 24).

Indicando ainda a falta de políticas públicas relacionadas ao grupo LGBT, descreve Garcia (2008, p. 6) "se não há o seu reconhecimento enquanto sujeitos, pelo próprio fato de não ocuparem um local definido nos 'catálogos' identitários reconhecidos na sociedade brasileira, torna-se evidentemente difícil sua inclusão como um segmento significativo nesse espaço público". 
O espaço escolar por exemplo, um dos primeiros espaços de identificação dos sujeitos nos grupos, também pode ter o preconceito social em sua rotina. A população trans em sua maioria desde muito cedo está as margens da sociedade, sem o acesso aos direitos básicos, não conseguindo um acesso digno à escolarização e ao mercado de trabalho em virtude do preconceito e da discriminação. Essas pessoas são rejeitadas de maneira precoce e vivenciam diversos tipos de violência durante suas vidas (Benevides \& Nogueira, 2020).

\section{A Dificuldade de Acesso ao Mercado de Trabalho}

Concomitantemente a essa realidade opressora, alguns movimentos do país visam a melhor qualidade de vida do grupo, como a Associação Nacional de Travestis e Transexuais (ANTRA) e o Grupo Gay da Bahia (GGB), que são associações de grande nome no Brasil. Existe o programa Brasil sem Homofobia, que pretende combater a violência e a discriminação contra a comunidade LGBT, seguindo os princípios de Yogyakarta, que visa enquadrar essa classe na rede de empregos, eliminando qualquer tipo de discriminação homofóbica ou transfóbica, e garantindo oportunidades de emprego para todos os níveis de competência, buscando, assim, assegurar a empregabilidade dessa classe (Vasconcellos, 2014).

Existe no momento, o programa online "Trans Emprego", que é um portal que disponibiliza o cadastro de currículo dessas pessoas e as direciona diretamente para vagas disponíveis de emprego. $\mathrm{O}$ programa ainda faz um apelo para as empregadoras, apontando a responsabilidade social para a atual realidade das pessoas travestis e transexuais brasileiras (Vasconcellos, 2014).

Nos resultados de sua pesquisa, Silva, Luppi e Veras (2020) indicam como uma necessidade para uma disputa mais equânime no mercado de trabalho formal as políticas públicas visando a redução do estigma e da discriminação a essa população, ampliando o acesso destes à escolarização e qualificação profissional. Assim, percebe-se, portanto, que mesmo sendo difícil o atual acesso da classe ao mercado de trabalho, lentamente estão surgindo grupos que discutem e fomentam a responsabilidade social sobre a exclusão dessas pessoas, e principalmente, buscam uma forma de resolvê-la. Essa pesquisa surgiu então como um auxílio na busca pela ampliação da responsabilidade social e se propôs a analisar as representações que as pessoas transexuais têm em relação ao mercado de trabalho, para que seja possível vislumbrar estratégias inclusivas e que ampliem a pertença social destas.

\section{Método}

Caracterizada pela formulação de questões e problemas para desenvolver hipóteses e atribuir no acesso do pesquisador ao ambiente do grupo, trata-se de uma pesquisa exploratória (Marconi \& Lakatos, 2010, p. 171). Mas também se observa de acordo com os objetivos da pesquisa que ela se caracteriza como descritiva, visto que seu foco será na descrição do conjunto de símbolos e sinais do grupo pesquisado. De acordo com Gil (2002, p. 42):

As pesquisas descritivas têm como objetivo primordial a descrição das características de determinada população ou fenômeno ou, então, o estabelecimento de relações entre variáveis. São inúmeros os estudos que podem ser classificados sob este título e uma de suas características mais significativas está na utilização de técnicas padronizadas de coleta de dados, tais como o questionário e a observação sistemática.

Para Gil (2002) a pesquisa-ação tem mostrado resultados positivos para pesquisadores que visam a participação como forma de pesquisa. Como a pesquisa será realizada com participação ativa e direta do pesquisador e dos grupos participantes, através da técnica de projeção para o futuro, esta será caracterizada como pesquisa-ação.

Participaram da pesquisa 5 pessoas que se consideraram pertencentes do grupo social de transexuais, destes 2 se identificaram como homens (18 e 19 anos) e 3 como mulheres (20, 23 e 47 anos). Todos já exerceram pelo menos uma atividade laboral na vida, 3 terminaram ensino médio e dois destes, 1 homem (19 anos) e 1 mulher (20 anos), estão na graduação. A pesquisa foi submetida e aprovada no comitê de ética em pesquisa através do parecer $\mathrm{N}^{\circ}$ 2.399.899 (CAAE 80039817.1.0000.0119) e os participantes assinaram um Termo de Consentimento Livre e Esclarecido (TCLE). O contato com os participantes ocorreu conforme a amostragem por cadeias de referência, que de acordo com Baldin e Munhoz (2011) seria a amostragem em Bola de Neve. 
Essa técnica é uma forma de amostra não probabilística utilizada em pesquisas sociais onde os participantes iniciais de um estudo indicam novos participantes que por sua vez indicam novos participantes e assim sucessivamente. Portanto, a snowball ("Bola de Neve") é uma técnica de amostragem que utiliza cadeias de referência, uma espécie de rede (Baldin \& Munhoz, 2011, p. 4).

De acordo com Sanchez e Nappo (2002), a técnica de Bola de Neve possibilita que o pesquisador se aproxime da população de amostra ao mesmo tempo em que fornece subsídios para a elaboração dos instrumentos de pesquisa. Dessa forma, o pesquisador tem a flexibilidade de reestruturar sua forma de investigação conforme conhece o grupo investigado.

Como critérios de inclusão foram estabelecidos: ter mais de 18 anos, ter tido alguma experiência no mercado de trabalho, identificar-se como transexual e ser da região de Criciúma (critério de acessibilidade). Os critérios de exclusão foram: ter menos de 18 anos, não ter experiência no mercado de trabalho e residir fora de Criciúma.

Para captação das representações sociais utilizou-se a Projeção para o Futuro, uma das técnicas do psicodrama, que visa explorar as expectativas de futuro, como o indivíduo acredita que este será, possibilitando a compreensão de sonhos, expectativas e até mesmo repetições do passado (Cukier, 1992). No caso dos grupos, sugere-se, dentro da técnica, novos encontros no futuro (dois anos, cinco anos depois, vinte ou trinta anos ou até mais) e em cada situação, as pessoas contam como estão, que mudanças aconteceram em suas vidas e como se sentem (Crelier, 1998). Assim, o uso da técnica permitiu que os participantes vivenciassem suas expectativas, auxiliando os pesquisadores na captação de RS relativas às práticas sociais e dados de realidade que permitem vislumbrar como pode ser esse futuro.

De acordo com Crelier (1993), o uso da projeção para o futuro permite uma reflexão acerca do momento presente e sobre a necessidade de mudança para o alcance do futuro desejado, possibilitando que o indivíduo se perceba criador do seu próprio futuro. A mesma se baseia nas etapas do psicodrama: um aquecimento, etapa na qual prepara-se o grupo para a ação dramática e coloca-os a se imaginar nesse futuro; a dramatização na qual os participantes se apresentam e falam no aqui e agora como se estivessem realmente no futuro; e o compartilhamento, momento no qual o participante fala de si, como se sentiu no momento. (Bustos, 2005).

\section{Resultado e Discussão}

O primeiro participante contatado foi a mulher transexual de 20 anos, através de um aplicativo de mensagens, os demais foram indicados pela rede de contatos desta participante. A aplicação da técnica ocorreu no espaço de Clínicas Integradas da Universidade do Extremo Sul Catarinense (UNESC), e teve duração média de 40 minutos. A técnica consistiu em fazer uma entrevista semiestruturada no primeiro momento, como estratégia de aquecimento. Conforme Cukier (1992) esta etapa tem como função auxiliar o protagonista a se desligar de assuntos aleatórios, objetivando adentrar e focalizar inteiramente os assuntos a serem trabalhados. Os temas da entrevista foram, dados de caracterização, definição de mercado de trabalho e experiências passadas no mercado de trabalho.

Em seguida, aplicou-se a técnica de projeção para o futuro, que tem a função de "ensaio de vida", agindo no sentido de aperfeiçoar habilidades e estratégias para lidar com situações, revitalizando sonhos e esperanças. Esta técnica dedica-se a construção de um sentido viável de futuro, da mesma forma que amplia as compreensões sobre o passado. Nesta, a pessoa é solicitada a colocar-se em um futuro e a descrever esse futuro como se estivesse vivendo-o no presente. Ao se vivenciar uma experiência futura no presente, abre-se então possibilidades de identificar-se metas alcançáveis e estabelecer o processo de alcance (Blatner, 1996).

Ao final da técnica foi garantido ao participante direito a devolutiva, esclarecendo eventuais dúvidas e assegurando o direito de desistência a qualquer momento da pesquisa.

As entrevistas semiestruturadas e os dados obtidos com a técnica de projeção para o futuro foram transcritos em um único corpus. Este corpus, foi submetido a uma Classificação Hierárquica Descendente (CHD) simples, com o auxílio do programa informático IRAMUTEQ versão 0.6. Este software gratuito viabiliza diferentes tipos de análise de dados textuais, desde aquelas bem simples, como a lexicografia básica, 
cálculo de frequência de palavras, até análises multivariadas como classificação hierárquica descendente e análises de similitude (Camargo \& Justo, 2013).

De acordo com Camargo e Justo (2013), a CHD visa obter classes de Segmentos de Texto (ST) que, ao mesmo tempo, apresentam vocabulário semelhante entre si e vocabulário diferente dos ST das outras classes. A CHD fornece os contextos textuais que se caracterizam pelo seu vocabulário, e segmentos de texto que compartilham esse vocabulário. O corpus de análise foi formado por Texto - que corresponderam às respostas dos participantes. Inicialmente o software reconhece os textos, e na análise standart o programa os secciona em ST (Segmento de Texto), que constituem o ambiente de enunciação da palavra, dando origem à unidade sobre a qual são feitos os cálculos estatísticos (Camargo \& Justo, 2013).

O programa IRAMUTEQ reconheceu a separação do corpus em 3 textos ou comentários. A CHD reteve os 5 textos e os separou em 51 segmentos de texto, estes foram selecionados por apresentarem frequência mínima de 3,0 por palavra e qui-quadrado mínimo de 3,84. O software dividiu o corpus em cinco classes, conforme indica a Figura 1.

Figura 1. Dendograma de classes sobre as as representações sociais do mercado de trabalho para transexuais

CHD

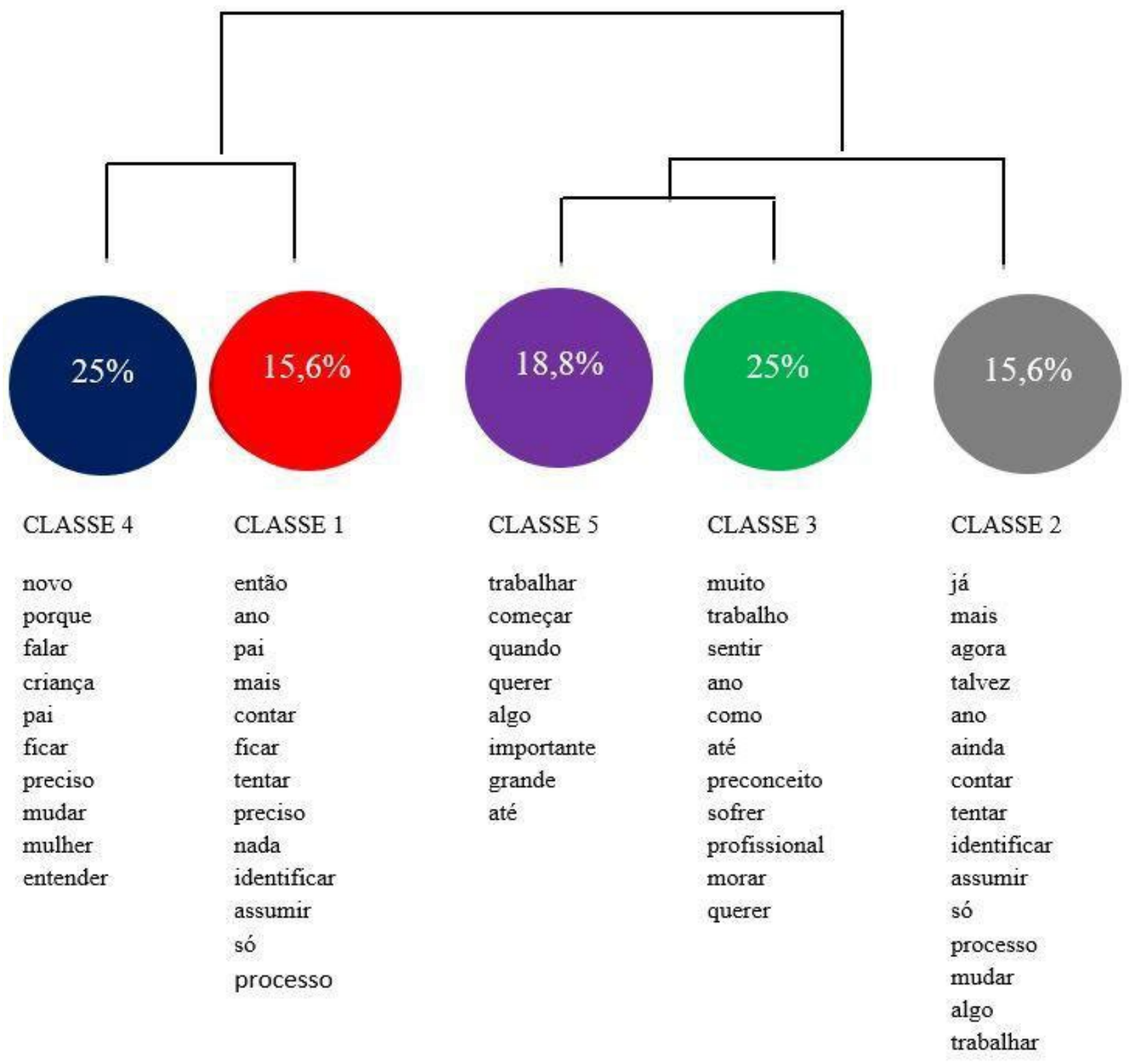


Num primeiro momento ( $1^{\text {a }}$ partição) o corpus foi separado em dois subcorpus (de um lado um conjunto formado pelas futuras classes 2, 3 e 5 e do outro pelas classes 1 e 4). Uma $2^{a}$ partição separou as classes 3 e 5 da classe 2 , posteriormente em uma $3^{a}$ partição as classes 3 e 5 se diferenciam entre si, e uma $4^{a}$ partição separou as classes 1 e 4.

A classe 2, Transição, relatada principalmente por transexuais homens, com 15,6\% dos comentários, traz a questão da transição na perspectiva da espera (em sua maioria), mas por outro lado uma participante relata o período de transição já efetivada via tratamento hormonal. Também foram relatadas perspectivas de projeção para o futuro no que concerne à finalização da transição. Ainda traz na palavra 'anos' a noção de tempo, em relação ao período em que se perceberam no corpo errado, bem como ao desejo futuro de efetivar a transição, após realização profissional. Ao ser questionado sobre planos futuros um participante homem transexual afirma: "Agora eu já estou bem mais masculino, já estou fazendo terapia hormonal há anos, talvez consiga minha cirurgia esse ano" (homem transexual, 19 anos, ensino superior incompleto).

Dessa forma, a cirurgia de redesignação surge como necessária para a finalização do processo de transgenerização identitário. Conforme Almeida (2018) a genitalização das identidades ainda estrutura as relações sociais. Nesse sentido as pessoas transexuais precisam lidar com a genitalização cultural. É preciso evidenciar que sexualidade tem relação tanto com as crenças, ideologias, representações, quanto com o corpo físico.

De acordo com Almeida (2018), mostra-se então necessário discutir sobre os papéis cristalizados em relação a gênero, bem como as feminilidades e masculinidades. É importante questionar as normas regulatórias de gênero e sexualidade. Almeida ainda destaca que homem e mulher além de representações sociais, são sistemas de classificação que comportam em si atribuição ou supressão de direito, deveres, privilégios e desvantagens.

Sobre a percepção em relação à identidade de gênero afirma um participante: "Com 11 anos eu me identificava como menina ainda, só preferia usar roupas mais neutras, mas ali pelos 14 anos comecei a me imaginar como homem, mudei bastante de estilo e comecei a pensar bastante coisas, sobre o que faltava na minha vida". (homem transexual, 19 anos, ensino superior incompleto). Aqui o participante fala da necessidade da mudança da expressão de gênero, em razão do sentimento de falta associado à identificação com um outro corpo. Sobre corpo, Nascimento (2013) destaca que este evoca normatização da vida cotidiana, englobando experiências singulares, tabus, crenças e expressões de desejo. Assim, as subjetividades sendo compostas por fluxos de desejo, constroem os sujeitos e se materializam nos corpos, seja por linha de fuga, de resistência, ou pela reprodução do que já é constituído.

O dado apresentado nesse segmento de texto é reforçado por elementos encontrados na pesquisa de Xavier e Sarat (2017, p. 5), onde as autoras apontam que "as memórias das entrevistadas relatam que em idade muito precoce, elas já tinham que lidar com conflitos como, desejar roupas diferentes do convencionado para seu sexo, a escolha dos brinquedos, etc." Assim o participante, ao refletir sobre identidade, materializa no corpo por meio da vestimenta a resistência à genitalização da sexualidade.

A classe 3, intitulada como "Experiências de trabalho no futuro e no passado" representa $25 \%$ do total de comentários. Seus textos apresentam os locais de trabalho e funções exercidas pelos participantes ao longo do histórico profissional e as profissões que gostariam de exercer no futuro. Como profissões exercidas atualmente são citadas: "transdrag', prostituta, atendente, bailarina e gerente." Ainda nessa classe a prostituição como meio de trabalho se mostra vinculada ao preconceito, como exemplificado no comentário a seguir: "sim há muito preconceito na área pra trabalho pra uma transexual, por isso muitas caiem na prostituição por não serem vista como um ser humano e poder ter a oportunidade de ser uma grande profissional de trabalho." (muIher transexual, 23 anos, ensino médio completo, transdrag e atendente). Nesse sentido, a prostituição surge, no discurso da participante, como única alternativa para algumas pessoas transexuais que não encontram oportunidade em outros contextos do mercado de trabalho.

\footnotetext{
1 *Transdrag: Transexual que trabalha com performance artísticas no estilo Drag Queen. São personagens criados por artistas performáticos que se travestem, fantasiando-se cômica ou exageradamente com o intuito geralmente profissional artístico.
} 
Confirmando esse pensamento, Almeida (2018) destaca que a inserção no mercado de trabalho é afetada pela condição transexual, na medida em que essas pessoas passam parte das trajetórias profissionais na informalidade, como forma de obter passibilidade, ou seja, de não serem percebidas na condição de transexual e assim não precisar apresentar documentação. Entretanto, considerar pessoas transexuais como sinônimo de profissionais do sexo é problemático, pois reafirma o preconceito existente naturalizando a desigualdade de acesso ao mercado de trabalho (Almeida, 2018).

Além disso, a baixa escolarização é determinante no mercado de trabalho formal, o que pode estar relacionado a busca pela prostituição como fonte de renda e sobrevivência. De acordo com Kaffer, Ramos, Alves e Tonon (2016) nos resultados de sua pesquisa, em muitas afirmações perceberam a prostituição vista como forma de subsistência, tanto por ser uma opção diante da dificuldade de permanência no mercado de trabalho formal, como também pela remuneração, já que ocupar vagas pouco valorizadas traria remunerações inferiores se comparadas aos ganhos com a prostituição.

O ambiente ideal de trabalho na classe 3 é relatado como aquele em que os outros funcionários desejam conhecer o novo profissional como pessoa, sem dar relevância ou destaque para questões de identidade ou gênero. O comentário a seguir representa o que foi exposto: “Então acredito que encontrei um ambiente onde essas questões não são importantes, eles querem te conhecer como pessoa, e fazer tu sentir parte." (homem transexual, 18 anos, médio completo, gerente). Nesta fala é possível perceber a importância de um ambiente de trabalho acolhedor no qual o sujeito se sinta incluído, pertencente a um grupo. Deschamps (2009), ao comentar sobre a Identidade Social, afirma que os indivíduos vivem com a necessidade de se sentir relativamente semelhantes ao outro, ao mesmo ponto que também buscam preservar sua unicidade e individualidade. Nesse sentido, a pessoa transexual deseja ser inserida no grupo, sem ter a necessidade de se enquadrar ao padrão heteronormativo e/ou binário em uma cultura organizacional.

A classe 5, nomeada "Primeiro Emprego", apresenta $18.8 \%$ dos segmentos de texto. Trata das primeiras experiências de trabalho dos participantes, dentre elas estão "profissional do sexo, estágio não obrigatório, costureira e atendente." Sobre essas experiências, os participantes relatam que nesse momento o apoio familiar é importante e que é percebida a ausência de pessoas transexuais no mercado de trabalho. Em seguida serão apresentados comentários que exemplificam essa classe: "eu tive bastante apoio familiar, desde quando comecei a me identificar como mulher. Trabalhei em algumas fábricas com costura e aí me dediquei a desenhar roupas." (mulher transexual, 20 anos, superior incompleto). A mesma participante ainda relata: "Essa experiência foi muito importante para mim, pois não encontrei pessoas transexuais trabalhando lá." Essa classe representa então a importância do suporte social, seja familiar ou entre pares, sugerindo a relevância de contar com o olhar ou com a presença do outro nesse momento de inserção no mercado de trabalho.

Sobre o suporte social, Brito e Cerqueira-Santos (2014) afirmam que a não inclusão social é potencializadora da má classificação da identidade do indivíduo transexual por outras pessoas, e a experiência de ter sua identidade reconhecida de forma errônea, pode ser causadora de problemas psicológicos. Uma representação é sempre construída socialmente, afirmando a necessidade de um debate social, e, para tanto a inclusão faz-se necessária. Conforme Jodelet (2005) em seu estudo sobre representações sociais da loucura, a representação do louco se faz em contraponto a representação da normalidade, em que, para que eu seja normal, faz-se necessário que exista a personificação e materialização da loucura. Nessa mesma direção, a normatização de gênero se faz na dicotomia do padrão binário em que um se faz heteronormal e o outro transgênero anormal.

No contexto dessa classe, a prostituição surge como trabalho inicial para alcance de objetivos futuros, mas que ao longo do tempo torna-se permanente. Como relatado por uma participante: “Comecei como temporário, agora pretendo continuar trabalhando com isso até quando der, estou pagando meu apartamento e quando terminar quero juntar um dinheiro e abrir algo para mim, mas ainda não pensei em nada." (mulher transexual, 47 anos, ensino médio completo, profissional do sexo). Assim, a prostituição encontra-se associada ao alcance de objetivos, e acaba, muitas vezes, se constituindo como única experiência de trabalho. 
Carvalho (2011) relaciona a recorrência de transexuais ao universo da prostituição e da criminalidade sendo a primeira alternativa dessas pessoas quando encontram em suas histórias de vida a rejeição familiar ou registros de violência sociais. Abreu et al. (2020) descrevem nos resultados de sua pesquisa, que o grupo percebeu que a prostituição se configura como uma alternativa de renda diante da exclusão social, principalmente das próprias famílias, de maneira violenta e precoce. Além disso, os autores ainda afirmam que a prostituição se produz como "um espaço de acolhimento e expressão da feminilidade, no entanto, que as expõem às situações de vulnerabilidade" (p. 4).

A classe 1, "Saindo do Armário", é representada por $15.6 \%$ dos segmentos de texto. Abrange relatos das experiências dos participantes nos momentos em que contaram para as pessoas afetivamente próximas sobre sua identidade de gênero. Experiências com pais, mães e alunos são relatadas e o relato mostra uma percepção negativa desse momento, como ilustrado a seguir:

Aí aos 16 anos eu me identifiquei como gênero fluído e desde então o F. foi ficando mais presente na minha vida, aí aos poucos fui me assumindo. No terceiro ano do ensino médio eu me assumi para os meus pais, mas não foi legal. Fiz uma carta para eles, mas só quem leu foi minha mãe e ela fingiu que nada aconteceu.

Depois de um ano em que troquei meu nome no facebook para $F$, meu pai descobriu, isso que minha mãe vivia brigando comigo sobre, mas ela não contava para ele. Aí ele ameaçou de me mandar embora se eu não trocasse, eu fiquei com medo porque ele é bem dramático e com a minha mãe nunca aconteceu nada, então eu fiz um post explicando para as pessoas o porquê de eu estar trocando tanto o nome e expliquei pra eles o diagnóstico que eu tive da terapia e foi aí que eles sentaram pra conversar (homem transexual, 19 anos, superior incompleto).

Neste trecho é possível perceber que a negação da transexualidade exercida pela mãe através da indiferença é identificada como algo negativo. Quando o participante torna pública a transição, mudando o nome na rede social, a indiferença dá espaço para brigas e ameaças. Possivelmente ocorra uma preocupação com o julgamento social, como comentado por Janini e Santos (2020, p.17), a família exerce um "poder discursivo para silenciar, coibir e até mesmo controlar a vivência da experiência transexual", o que ocasiona sentimentos de não pertencimento, de incompreensão e de sofrimento.

Ainda nessa classe, após a "Saída do Armário" há um segmento de texto que relata a exclusão sofrida pela pessoa transexual no mercado de trabalho. Como no comentário a seguir:

[...] como transexual não consegui emprego, por conta do preconceito em si, porque quando éramos pra fazer entrevista a gente se mostrava fisicamente uma pessoa e os documentos eram com nome masculino, então eles

falavam 'então a gente está procurando outra pessoa com outro tipo de perfil e tudo mais' (mulher transexual, 23 anos, ensino médio completo, transdrag e atendente).

O relato mostra a importância da legitimidade oferecida pelo nome social, já que quando documentos não conferem com a aparência, parecem surgir mais ações de exclusão por parte do empregador. Neste contexto a expressão "você não se enquadra no perfil" surge como mecanismo implícito de promoção à discriminação. Bento (2014) faz uma crítica à legislação Brasileira, que garante em instituições como universidades, escolas e órgãos públicos o direito e respeito à identidade de gênero e ao nome social, mas o mesmo não se aplica ao mercado de trabalho e outras dimensões da vida do sujeito. Como pontuado pela autora, para que as pessoas transexuais tivessem acesso à mudança de seu nome no registro civil, pelo menos até fevereiro de 2018, era necessário um laudo médico, e ainda assim dependia da decisão do juiz. Fica claro que a legislação se mostra redundante, pois em algumas áreas sociais a pessoa tem o direito de determinar sua identidade de gênero, enquanto em outras isso se torna responsabilidade de um terceiro.

A classe 4, denominada "Percepção Social", com 25\% de segmentos de texto, apresenta trechos que fazem menção a como os participantes percebem a recepção nos espaços sociais que frequentam. Seguem alguns relatos que exemplificam o exposto:

Falei para as crianças que eu tinha nascido como Kauã, mas tinha me tornado Maria Rita (nome de uns alunos),

e eles entenderam da forma deles, eles falam que eu tinha a força de menino, mas era delicada como uma menina, e contaram isso para os pais. Aí eu expliquei que era transexual, mas que isso não interferia no meu trabalho com as crianças, que era algo meu, da minha personalidade (mulher transexual, 20 anos, superior incompleto). 
Esse segmento de texto demonstra que o preconceito pode ser constituído socialmente, pois para as crianças, a transexualidade torna-se apenas mais uma característica daquela pessoa, constituída por tantas outras características. Janini e Santos (2020) afirmam que o preconceito e a discriminação são ensinados e reforçados pela sociedade e pela cultura familiar e social. De acordo com Oliveira, Rosato, Nascimento e Granja (2018), as pessoas trans são impedidas pela sociedade de vivenciar situações e relações comuns para a maioria da sociedade, como: acesso a escolarização, contexto familiar, cuidado com a saúde, oportunidades no mercado de trabalho e outras. O ambiente familiar torna-se violento de diversas maneiras; as escolas não conseguem acolher e auxiliar nas demandas; o mercado de trabalho fica limitado. Suas vivências ficam limitadas aos espaços marginalizados e caóticos.

Outra forma de percepção social apontada nessa classe, que se assemelha à um trecho relatado na classe 1, é demonstrada pelos pais, que temem a exposição da transexualidade do filho. "Disseram que se eu for assim, não preciso expor para o mundo." (homem transexual, 19 anos, superior incompleto). Identifica-se novamente que a transexualidade surge como algo a ser escondido, como se fosse imoral.
Ainda nesta classe encontra-se um segmento de texto que menciona os estereótipos relacionados à transexualidade percebidos nos olhares dos outros. A seguir um relato ilustrativo:

\section{[...] Eu sofria preconceito inicial, nas prefeituras e sedes} dos eventos, mas logo que eu abria a boca percebia que os olhares mudavam. As pessoas iam tirando de mim a imagem desse rótulo, e é claro que esse rótulo existe porque tem muitas mulheres transexual que realmente não valem nada (mulher transexual, 47 anos, profissional do sexo, ensino médio completo).

É perceptível que nesse comentário também, a própria mulher transexual, apresenta uma representação estereotipada do que é ser trans. Associando muitas muIheres transexuais à condição de menos valia. Barbosa (2010) aponta a existência do preconceito entre transexuais, relacionado ao fato de umas se sentirem mais femininas e alegarem que as outras, que trabalham com a prostituição, beiram o exagero, colocando isso como uma abertura para a discriminação social.

Na figura 2 são apresentadas as palavras de maior frequência em todas as classes, as palavras centrais constituem o núcleo da representação social do mercado de trabalho, dando sentido às falas dos participantes.

Figura 2. Nuvem de Palavras com a síntese dos resultados

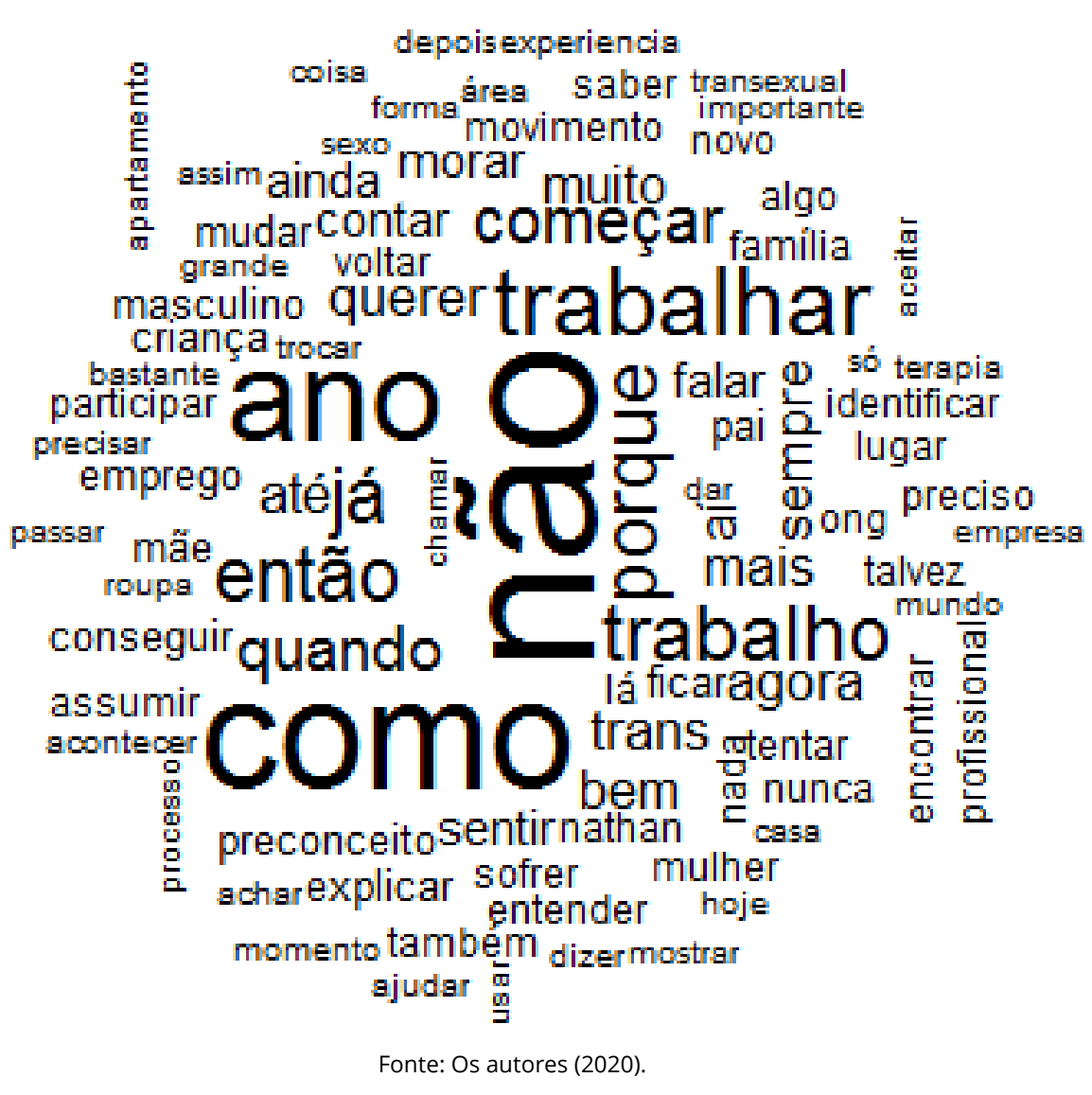


Assim, palavras como trabalhar, não, começar, morar, ficar, transexual, preconceito, compõem os segmentos de texto que retratam a percepção social (os olhares de aceitação e julgamento), a saída do armário (retrata as dificuldades de aceitação social no momento de transição), primeiro emprego (que fala sobre a ausência de pessoas transexuais no mercado de trabalho e a prostituição como única opção, em muitos casos), experiências de trabalho no futuro e no passado (remetem a importância do acolhimento da equipe de trabalho) e transição (segmento que abrange as questões referentes à percepções de si e do processo de transição).

\section{Considerações Finais}

O desenvolvimento do estudo promoveu acesso às representações sociais de transexuais, no qual foi possível perceber a influência que o preconceito social tem na formação da carreira da população que serviu de amostra para a pesquisa. Dessa forma, concorda-se com Brito e Cerqueira-Santos (2014) quando apontam que entre as formas de se pensar corpo e identidade, acredita-se que a construção da identidade social e profissional das pessoas transexuais é fortemente influenciada pela relação e redes de apoio sociais estabelecidas.

Torna-se evidente então a necessidade de modelos de intervenções sociais, cujo objetivo seja de encontrar, através das representações sociais, formas de acesso ao direito à cidadania para pessoas transexuais. Como ressaltado por Bento (2014) a própria existência trans pede que haja novos projetos para a humanidade em outros termos, onde se deve ter 0 pleno reconhecimento das pessoas trans como pertencentes da cidadania.

Através da técnica de Projeção do Futuro, os participantes puderam vivenciar cenas nas quais seus desejos profissionais para os próximos anos fossem realizados. Crelier (1998) coloca essa vivência como potencializadora para a tomada de ações, onde o indivíduo consegue se apropriar de forma mais palpável de seu interesse futuro. Destacam-se como limitações do estudo o número de participantes, tendo em vista a necessidade da escuta de outras perspectivas e experiências; e a escolaridade dos participantes, todos com ensino médio e alguns na graduação, o que de acordo com outros estudos não seria a realidade da maioria da população trans (Almeida \& Vasconcellos, 2018; Silva, Luppi \& Veras, 2020)..

Finalmente, sugere-se, que mais pesquisas abordando essa comunidade, e principalmente as representações sociais operantes para o público, sejam realizadas, a fim de potencializar novos modelos de intervenções sociais, acesso ao mercado de trabalho e novas representações sociais.

\section{Contribuições dos autores}

Lopes RAG participou da concepção, delineamento, busca e análise dos dados da pesquisa, interpretação dos resultados, redação do artigo científico. Kern CAR participou da concepção e delineamento da pesquisa. Castro A participou da concepção, delineamento, análise estatística dos dados da pesquisa, interpretação dos resultados, redação e revisão. Vidal GP participou da análise dos dados da pesquisa, interpretação dos resultados e redação do artigo científico.

\section{Conflitos de interesses}

Nenhum conflito financeiro, legal ou político envolvendo terceiros (governo, empresas e fundações privadas, etc.) foi declarado para nenhum aspecto do trabalho submetido (incluindo, mas não se limitando a subvenções e financiamentos, participação em conselho consultivo, desenho de estudo, preparação de manuscrito, análise estatística, etc.).

\section{Referências}

Abreu, P. D., Araújo, E. C., Vasconcelos, E. M. R., Ramos, V. P., Moura, J. W. S., Santos, Z. C., ... Santos, C. B. (2020). Representações sociais de mulheres transexuais vivendo com HIV/Aids. Revista Brasileira de Enfermagem, 73(3), e20180390. http://dx.doi.org/10.1590/0034-7167-20180390

Abric, J.C. A abordagem estrutural das representações sociais. In Moreira, A.S.P.,\& Oliveira, D.C. Estudos interdisciplinares de representação social (pp. 27-46). AB

Allport, G.W. (1979). The nature of prejudice. Basic Books.

Almeida, A. M. O., Santos, M. F. S., \& Trindade, Z. A. (2000). Representações e práticas sociais: contribuições teóricas e dificuldades metodológicas. Temas em Psicologia, 8(3), 257-267. http://pepsic.bvsalud.org/scielo.php?script=sci_ arttext\&pid=S1413-389X2000000300005 
Almeida, G. (2018). Identidades de gênero com ênfase nas pessoas trans: particularidades e acesso à saúde, trabalho e educação. In Nogueira, L., Hilário, E., Paz, T. T., Marro, K. (Orgs.). Hasteemos a Bandeira Colorida: Diversidade sexual e de gênero no Brasil. Editora Expressão Popular.

Almeida, C. B., \& Vasconcellos, V. A. (2018). Transexuais: transpondo barreiras no mercado de trabalho em São Paulo?. Revista Direito GV, 14(2), 303-333. https://doi. org/10.1590/2317-6172201814

Baldin, N., \& Munhoz, E. M. B. (2011). Snowball (bola de neve): uma técnica metodológica para pesquisa em educação ambiental comunitária. X Congresso Nacional de Educação - EDUCERE, Pontifícia Universidade Católica do Paraná, Curitiba, PR, Brasil. https://docplayer.com.br/1714932Snowball-bola-de-neve-uma-tecnica-metodologica-parapesquisa-em-educacao-ambiental-comunitaria.html

Barbosa, B. C. (2010). Nomes e diferenças: uma etnografia dos usos das categorias travesti e transexual (Dissertação de Mestrado, Universidade de São Paulo). https://www.teses. usp.br/teses/disponiveis/8/8134/tde-09032010-115929/ pt-br.php

Benevides, B. G., \& Nogueira, S. N. B. (2020). Dossiê dos assassinatos e da violência contra travestis e transexuais brasileiras em 2019. Expressão Popular, ANTRA, IBTE.

Bento, B. A. M. (2008). O que é transexualidade (Coleção Primeiros Passos). Brasiliense.

Bento, B. (2014). Nome social para pessoas trans: cidadania precária e gambiarra legal. Contemporânea-Revista de Sociologia da UFSCar, 4(1), 165-182. http://www. contemporanea.ufscar.br/index.php/contemporanea/ article/view/197

Blatner, A. (1996). Uma visão global do psicodrama: fundamentos históricos, teóricos e práticos. Ágora.

Camargo, B. V., \& Justo, A. M. (2013). "IRAMUTEQ: um software gratuito para análise de dados textuais". Temas em Psicologia, 21(2): 513-518. http://dx.doi.org/10.9788/ TP2013.2-16

Carvalho, M. F. L. (2011). Que mulher é essa: identidade, política e saúde no movimento de travestis e transexuais (Dissertação de Mestrado, Universidade do Estado do Rio de Janeiro). http://www.bdtd.uerj.br/tde_busca/arquivo. php?codArquivo $=2621$

Cerqueira, M. (2016). Assassinatos de LGBTs no Brasil: Relatório 2016, GGB. http://bancariospa.org.br/wp3/wp-content/ uploads/2017/01/relatc3b3rio-20162.pdf
Crelier, V. (1998). Projeção para o futuro. In Monteiro, R.F. (Org.). Técnicas fundamentais do psicodrama (pp. 85-91). Editora Brasiliense.

Cukier, R. (1992). Psicodrama bipessoal: sua técnica, seu terapeuta e seu paciente. Ágora.

Deschamps, J. C., Moliner, P. (2009). A identidade em psicologia social: dos processos identitários às representações sociais. Vozes.

Garcia, M. R. V. (2008). Prostituição e atividades ilícitas entre travestis de baixa renda. Cadernos de Psicologia Social do Trabalho, 11(2), 241-256. http://pepsic.bvsalud. org/scielo.php?script=sci_abstract\&pid=S1516$37172008000200008 \&$ Ing=pt\&nrm=iso

Gil, A. C. (Org.). (2002). Como elaborar projetos de pesquisa. Atlas.

Goerch, A. B., \& Silva, D. R. Q. (2019). Inclusão social e diversidade de gênero de pessoas transexuais no mercado de trabalho brasileiro. Seminário Internacional Demandas Sociais e Políticas Públicas na Sociedade Contemporânea. https://online.unisc.br/acadnet/anais/index.php/sidspp/ article/view/19615/1192612330

Goffman, E. (2004). Estigma: notas sobre a manipulação da identidade deteriorada. LTC.

Gomes, D. A. S. (2009). No "bate porta": a trajetória das travestis, em situação de prostituição, em Taguatinga (Trabalho de Conclusão de curso, Universidade de Brasília). https:// bdm.unb.br/handle/10483/1290

Janini, J. P., \& Santos, R. S. (2020). Relações sócio-familiares e a construção da personalidade da pessoa transexual. Research, Society and Development, 9(9), e677997883-e677997883. https://doi.org/10.33448/rsdv9i9.7883

Jodelet, D. (2001). Representações sociais: um domínio em expansão. In D. Jodelet. (Org.). As representações sociais (pp.17-29). EDUERJ.

Jodelet, D. (2005). Loucuras e representações sociais. Vozes.

Kaffer, K. K., Ramos, F. G., Alves, A. L., \& Tonon, L. (2016). A transexualidade e o mercado formal de trabalho: principais dificuldades para a inserção profissional. Anais do Congresso Brasileiro de Estudos Organizacionais. https:// anaiscbeo.emnuvens.com.br/cbeo/article/viewFile/52/44

Marconi, M. A., \& Lakatos, E. M. (2010). Fundamentos de metodologia científica. Atlas.

Moscovici, S. (1978). A representação social da psicanálise. Zahar. 
Mott, L. R. B., \& Cerqueira, M. F. (2003). Matei porque odeio gay. Editora Grupo Gay da Bahia.

Nascimento, M. A. N. (2013). Corporalidade fora dos eixos: a insurgência dos prazeres e modificações culturais na transcontemporaneidade. In F. S. Teixeira Filho, W. S. Peres, C. A. Rondini, L. L. Souza (Orgs.). Queering, problematizações e insurgências na Psicologia Contemporânea. Edu FMT.

Oliveira, J. W., Rosato, C. M., Nascimento, A. M. R., \& Granja, E. (2018). "Sabe a Minha Identidade? Nada a Ver com Genital": Vivências Travestis no Cárcere. Psicologia: Ciência e Profissão, 38(SPE2), 159-174. https://doi. org/10.1590/1982-3703000212382

Rago, L. M. (1991). Os prazeres da noite: prostituição e códigos da sexualidade feminina em São Paulo, 1890-1930 (Tese de Doutorado, Universidade Estadual de Campinas, Instituto de Filosofia e Ciencias Humanas). http://repositorio. unicamp.br/jspui/handle/REPOSIP/325802

Sanchez, Z. V. M., \& Nappo, S. A. (2002). Seqüência de drogas consumidas por usuários de crack e fatores interferentes. Revista Saúde Pública, 36(4), 420-430. https://doi. org/10.1590/S0034-89102002000400007
Silva B., B., \& Cerqueira-Santos, E. (2014). Apoio e suporte social na identidade social de travestis, transexuais e transgêneros. Revista da SPAGESP 15(2), 27-44. http://pepsic.bvsalud.org/scielo.php?script=sci_ arttext\&pid=S1677-29702014000200004

Silva, M. A., Luppi, C. G., \& Veras, M. A. S. M. (2020). Trabalho e saúde na população transexual: fatores associados à inserção no mercado de trabalho no estado de São Paulo, Brasil. Ciência \& Saúde Coletiva, 25(5), 1723-1734. https:// doi.org/10.1590/1413-81232020255.33082019

Vasconcellos, L. T. (2014) Travestis e transexuais no mercado de trabalho. $X$ Congresso nacional de excelência em gestão. FIRJAN, Rio de Janeiro, RJ, Brasil. https://www.inovarse.org/ sites/default/files/T14_0409.pdf

Xavier, N. R., \& Sarat, M. (2017). Memórias da família e escola: relatos de mulheres transgêneras a partir da história oral". IV Encontro de História da Educação do Centro-Oeste (EHECO), UEMS, Campo Grande, MS, Brasil.

Zanelli, J. C., \& Silva, N. (1996). Programa de preparação para aposentadoria. Insular. 